\title{
Uso de la tintura de propóleo al $0,12 \%$ en un paciente con enfermedad periodontal y agrandamiento gingival
}

\section{Use of $0.12 \%$ propolis tincture in a patient with periodontal disease and gingival enlargement}

\section{Uso de tintura de própolis a 0,12\% em paciente com doença periodontal e aumento gengival}

\author{
Verónica E. Salazar-Caicedo ${ }^{1}$ \\ verito123_24@hotmail.com \\ Mariela C. Balseca-Ibarra" \\ mblaseca@uce.edu.ec \\ Alicia C. Martínez-Martínez "II \\ aliciacomartinez@hotmail.com
}

Recibido: 12 de noviembre de 2016 * Corregido: 11 de enero de $2017 *$ Aceptado: 13 de enero de 2017

\footnotetext{
'Odontóloga, Facultad de Ciencias Médicas de la Salud y la vida, Escuela de Odontología, Universidad Internacional del Ecuador, Quito, Ecuador.

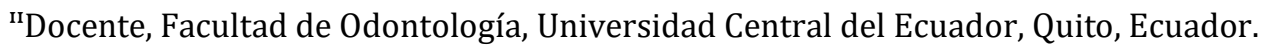

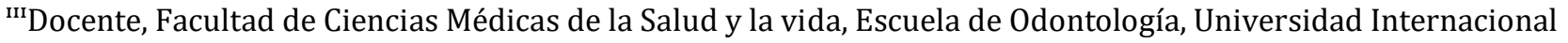
del Ecuador, Quito, Ecuador.
} 


\section{Resumen.}

Objetivo: Devolver la salud y estética gingival al paciente, con un menor tiempo de cicatrización por medio del uso de la tintura de propóleo al $0.12 \%$. Materiales y métodos: Se colocó tintura de propóleo al $0,12 \%$ posterior a la terapia básica periodontal y cirugía plástica periodontal en un paciente con enfermedad periodontal, agrandamiento gingival e inserción alta del frenillo. Después de la terapia básica periodontal el propóleo fue colocado por medio de torundas de algodón embebidas en tintura de propóleo y se repitió el procedimiento 24 y 48 horas después de la intervención. Para la recuperación de la cirugía plástica periodontal se realizó una comparación entre el uso de un apósito de óxido de zinc-eugenol en los cuadrantes inferiores, y el uso de la tintura de propóleo al 0,12\% en forma de goteo en los cuadrantes superiores. Se recetó al paciente ibuprofeno de 600mg cada 8 horas y se solicitó que llene las encuestas subjetivas del dolor. Resultados: Se observó un gran poder cicatrizante de la tintura de propóleo el 0,12\%. El paciente no tuvo la necesidad de tomar medicamento después de la terapia básica periodontal, y al tercer día de realizada la cirugía plástica periodontal el tejido gingival del cuadrante superior mostró un gran avance en su cicatrización en comparación con el tejido protegido por el apósito de óxido de zinceugenol en los cuadrantes inferiores. Conclusiones: El propóleo funcionó como un excelente cicatrizante en el tejido gingival reduciendo las molestias y tiempo de cicatrización de los tejidos. Además, se comprobó que actúa como un excelente hemostático.

Palabras clave: Propóleos; periodontitis; agrandamiento gingival; cirugía plástica periodontal; cicatrización. 


\section{Abstract.}

Objective: To return gingival health and aesthetics to the patient, with a shorter healing time through the use of $0.12 \%$ propolis tincture. Materials and methods: A $0.12 \%$ propolis tincture was placed after periodontal basic therapy and periodontal plastic surgery in a patient with periodontal disease, gingival enlargement and high frenulum insertion. After basic periodontal therapy the propolis was placed through cotton swabs embedded in propolis tincture and the procedure was repeated 24 and 48 hours after the intervention. For the recovery of periodontal plastic surgery, a comparison was made between the use of a zinc oxide-eugenol dressing in the lower quadrants and the use of $0.12 \%$ dye-dye in the upper quadrants. The patient was prescribed 600mg ibuprofen every 8 hours and was asked to complete the subjective pain surveys. Results: A high healing power of propolis tincture was observed at $0.12 \%$. The patient had no need to take medication after basic periodontal therapy, and on the third day of periodontal plastic surgery the upper quadrant gingival tissue showed a breakthrough in healing compared to the tissue protected by the oxide dressing Of zinc-eugenol in the lower quadrants. Conclusions: Propolis worked as an excellent cicatrizant in the gingival tissue reducing the discomfort and time of healing of the tissues. In addition, it was found to act as an excellent hemostat.

Key words: Propolis; periodontitis; gingival enlargement; periodontal plastic surgery; cicatrization. 


\section{Resumo.}

Objetivo: Retornar a saúde e a estética gengival ao paciente, com menor tempo de cicatrização através do uso de tintura de própolis 0,12\%. Materiais e métodos: Após a terapia básica periodontal e a cirurgia plástica periodontal, foi colocada uma tintura de própolis $0,12 \%$ em paciente com doença periodontal, aumento gengival e inserção alta do frênulo. Após a terapia periodontal básica, a própolis foi colocada através de cotonetes embutidos em tintura de própolis e o procedimento foi repetido 24 e 48 horas após a intervenção. Para a recuperação da cirurgia plástica periodontal, foi feita uma comparação entre o uso de um curativo de óxido de zinco-eugenol nos quadrantes inferiores eo uso de corante de corante de $0,12 \%$ nos quadrantes superiores. O paciente foi prescrito ibuprofeno 600mg a cada 8 horas e foi convidado para completar os inquéritos de dor subjetiva. Resultados: Foi observado um poder de cura elevado da tintura de própolis a $0,12 \%$. O paciente não teve necessidade de tomar medicação após a terapia periodontal básica e no terceiro dia de cirurgia plástica periodontal o tecido gengival do quadrante superior mostrou um avanço na cicatrização em relação ao tecido protegido pelo curativo de óxido de zinco-eugenol nos quadrantes inferiores. Conclusões: A própolis funcionou como excelente cicatrizante no tecido gengival, reduzindo o desconforto eo tempo de cicatrização dos tecidos. Além disso, verificou-se actuar como um excelente hemostato.

Palavras chave: Própolis; periodontite; ampliação gengival; cirurgia plástica periodontal; cicatrização. 


\section{Introducción.}

Las afecciones bucales constituyen un importante problema de salud por su alta prevalencia, impactando fuertemente sobre las personas y la sociedad en términos de dolor, molestias, limitaciones y discapacidad social y funcional, así como también por su efecto sobre la calidad de vida de la población. (1)

Las enfermedades periodontales son un grupo de enfermedades de carácter infeccioso que afectan a los tejidos que rodean y sostienen a los dientes. (2) Es la gingivitis el tipo de enfermedad periodontal que se observa con más frecuencia en los niños y adolescentes, y es un proceso inmunoinflamatorio reversible de los tejidos blandos que rodean al diente que se caracteriza por enrojecimiento, edema y sangrado gingival. Si esta afección no es precozmente diagnosticada y tratada, puede evolucionar hacia una lesión más compleja en el adulto: la periodontitis, caracterizada por la pérdida del sostén óseo, presencia de bolsas periodontales y movilidad dentaria entre otros signos. (1)

El objetivo del raspado y el alisado es restituir la salud gingival, eliminando por completo los elementos que provocan la inflamación de la encía (placa, cálculo y endotoxinas) La palabra raspado designa la remoción de depósitos de la superficie dentaria, esta acción se incluye al realizar los procedimientos de tartrectomía y durante cualquier cirugía, ya sea a colgajo, o para solucionar defectos mucogingivales. La palabra alisado designa las maniobras que se realizan para remover la superficie del cemento o dentina contaminada y establecer una superficie lisa, sin elementos tóxicos y biológicamente aceptables para que se inserten las nuevas fibras del desmodonto. (3) 
El término hiperplasia se refiere al aumento de tamaño de los tejidos en un órgano, producido por el aumento del número de sus componentes celulares. (4). Los agrandamientos gingivales inespecíficos se producen por una relación hiperplásica del tejido inflamatorio crónico relacionada con factores locales como placa bacteriana, cálculos y bacterias (4). La placa bacteriana, presente en todos los individuos, es capaz de producir alteraciones gingivales, especialmente cuando se combina con la presencia de aparatos ortodóncicos, que requieren una duración del tratamiento entre 18 y 24 meses. (4)

Diversos son los efectos dañinos que se reportan por la literatura nacional e internacional en los pacientes con tratamiento ortodóncico debido a la mala higiene bucal durante la terapéutica. Los aparatos ortodóncicos están dentro de los factores que proporcionan el acúmulo de placa bacteriana, la cual favorece la aparición de inflamación gingival, conocido como gingivitis, que en dependencia de su severidad, pueden evolucionar y derivar en problemas más graves como periodontitis, daño de las estructuras de los tejidos de soporte de los dientes. (5)

Uno de los tratamientos para la hiperplasia o agrandamiento gingival es la gingivectomía, para eliminar todo el tejido fibrótico que rodea a la pieza dental, y al mismo tiempo se realiza un contorneo o remodelamiento de la gíngiva llamado gingivoplastía. Esta técnica busca eliminar bolsas supraóseas, agrandamientos fibrosos o edematosos de la encía, transformación de márgenes redondeados o engrosados en la forma ideal, abscesos periodontales supraóseos. (6)

El propóleo, o própolis, designa algunas sustancias gomosas y resinosas que, segregadas por la corteza y yemas de algunas plantas, son procesadas con secreciones glandulares de las abejas, hasta conseguir el producto final, conocido como propóleo. Va a ser utilizado para diferentes necesidades de la colmena, tales como pegar fuertemente las partes móviles o rompibles que puedan 
caer, o evitar posibles infecciones en la colmena, constituyendo de esta manera una especie de barrera en la entrada de la colmena. (7)

La excelente acción antiséptica observada, añadida a las propiedades antiinflamatorias y cicatrizantes, conocidas desde hace tanto tiempo, y su uso en la medicina popular en el tratamiento de callosidades, heridas, quemaduras, etc., dio paso a investigaciones en las que ciertos bioflavonoides contenidos en esta sustancia (principalmente la quercitina y la galangina) eran los responsables de la actividad bacteriostática (detención del desarrollo de las bacterias) y bactericida (destructor de bacterias). Pero además, el propóleo tiene una excelente acción antiinflamatoria, cicatrizante, anestésica y activadora de los mecanismos inmunológicos. (7)

El efecto que ha tenido el propóleo sobre el periodonto ha sido de gran satisfacción puesto que ha demostrado tener actividad antiinflamatoria, antimicrobiana, anestésica y cicatrizante, en casos de gingivitis crónicas y úlceras bucales recurrentes e inespecíficas; siendo de ayuda para mejorar el tratamiento periodontal, más aún si tenemos en cuenta que la consecuencia fundamental a largo plazo es la pérdida de todos los dientes. (8)

Sobre la base de este conocimiento nos propusimos utilizar la tintura de propóleo al 0,12\% como cicatrizante en un paciente con enfermedad periodontal y agrandamiento gingival, con el objetivo de evaluar y comparar su efecto cicatrizante, antiinflamatorio y hemostático en procedimientos invasivos como son la terapia básica periodontal y la cirugía plástica periodontal. 


\section{Materiales y métodos.}

Se realizó un estudio observacional comparativo y descriptivo en el área de Periodoncia en la clínica de la Universidad Internacional del Ecuador, en el periodo comprendido entre Noviembre, 2014 y Mayo, 2015. La muestra estuvo constituida por un paciente de veintidós años que cumplió con los siguientes criterios: consentimiento informado, diagnóstico clínico de enfermedad periodontal y agrandamiento gingival, y test de alergia a propóleos negativo. El paciente es fumador activo, pero por motivos de la investigación se le solicitó que anule su hábito para mejores resultados.

Una vez diagnosticada la enfermedad objeto de nuestro estudio, se comenzó por realizar una profilaxis y terapia básica periodontal en los dientes con sondaje mayor de $3 \mathrm{~mm}$ para tratar la enfermedad periodotal, Para la terapia básica periodontal se utilizó el ultrasonido y las curetas de Gracey para lograr la eliminación de bolsas y pseudobolsas periodontales. Una vez finalizado, se colocó la tintura de propóleo al 0,12\% en las encías con la ayuda de torundas de algodón empapadas en tintura de propóleo. Para calmar el dolor por la manipulación de los tejidos, se le recetó al paciente ibuprofeno de $600 \mathrm{mg}$ cada 8 horas por 3 días, y para tener una buena antisepsia, se le receta enjuague bucal a base de clorhexidina al 0,12\% por 15 días, 30 minutos después del cepillado, 2 veces al día. A los 30 min, y 24 horas después de la terapia básica periodontal, se le solicita al paciente que complete la encuesta de los síntomas subjetivos del dolor.

Ocho días después de realizada la terapia básica periodontal, se solicita al paciente que complete la encuesta de los síntomas subjetivos del dolor, y se realizó un control de la evolución de los tejidos y un nuevo índice de placa para comprobar si el paciente cambió sus hábitos de higiene bucal. A los 15 días de la intervención se reevaluaron los tejidos periodontales del paciente por 
medio de la nueva toma de mediciones del margen gingival y la profundidad de sondaje para determinar el nivel real de agrandamiento gingival ya que la inflamación ha sido reducida.

Una vez determinado el nivel real de agrandamiento gingival, se procedió a realizar la cirugía plástica periodontal. Se comenzó por anestesiar al paciente tanto en sus cuadrantes superiores como inferiores. Con la sonda CP-15 se procedió a la medición de la relación del margen gingival con respecto al límite amelocementario, y a su vez de la relación de los dos con la cresta alveolar, consiguiendo así la medida del ancho biológico. Las medidas del ancho biológico dictaron que para todos los dientes de canino a canino solo se necesitaba realizar una gingivectomía sin ostectomía y gingivoplastía en los cuadrantes superiores e inferiores. En adición, se observó que el frenillo superior tenía una inserción muy baja, por lo que se realizó la frenectomía de este. Una vez finalizado, se colocó un apósito de óxido de zinc-eugenol en el cuadrante inferior, mientras que en el cuadrante superior se colocó la tintura del propoleo al $0.12 \%$ para comparar resultados.

A las 24 y 48 horas de haber sido realizada la cirugía plástica periodontal se efectuó un control para evaluar la evolución de los tejidos tratados quirúrgicamente. En el control de las 48 horas se realizó la remoción del apósito quirúrgico de los dientes inferiores. A los ocho días se removieron los puntos de la frenectomía y se colocó tintura de propóleo al $0.12 \%$.

Después de cada control que se le realizó al paciente se le solicitó que complete una encuesta subjetiva del dolor para medir los resultados. 


\section{Presentación caso clínico.}

Paciente masculino de 22 años de edad acude a la Clínica de Especialidades Odontológicas de la Universidad Internacional del Ecuador el 22 de Noviembre del 2014 refiriendo que le sangran las encías desde hace dos años posteriores a la colocación de aparatología de ortodoncia, y que no ha recibido ningún tipo de tratamiento para dicha molestia.

El paciente es fumador activo, no presenta enfermedades sistémicas de relevancia, pero refiere que tiene rinitis alérgica. Tuvo tratamiento ortodóntico de 2 años de duración y le han realizado sellantes y restauraciones de resina previamente.

El paciente presenta un tipo craneal braquicefálico, simetría facial, musculatura masticatoria buena, apertura bucal adecuada y ATM sin patología, ganglios linfáticos sin patología y normales a la palpación.

Al examen intraoral, en los cuadrantes superior e inferior se observó agrandamiento gingival con inflamación que se extienda de canino a canino, y coronas clínicas cortas. El paciente presenta un biotipo periodontal grueso. En el cuadrante superior se observó inserción alta del frenillo, mientras que en el cuadrante inferior se observó inserción normal del frenillo lingual y glándulas salivales normales. Se observó la presencia de un alambre de contención en las caras linguales de los dientes anteroinferiores por motivos ortodónticos.

Las encías del paciente no presentaban las características de una encía saludable, sino que se observó encías agrandadas con los márgenes gingivales de los dientes anteriores cubriendo un tercio de la corona clínica, el festoneado alterado, una coloración roja intensa y el punteado en cascara de naranja ausente. Se observó también gran cantidad de cálculo supragingival en las caras linguales de 
los dientes anteroinferiores. Al sondaje se observó que el paciente tenía varias bolsas y pseudobolsas periodontales con medidas mayores a $3 \mathrm{~mm}$.

\section{Diagnóstico}

Periodontitis crónica moderada localizada asociada a biofilm duro y blando, y tabaquismo. Deformidad mucogingival: agrandamiento gingival a causa de aparatos ortodónticos, e inserción alta del frenillo labial. (Figura $\left.N^{\circ} \mathbf{1}\right)$
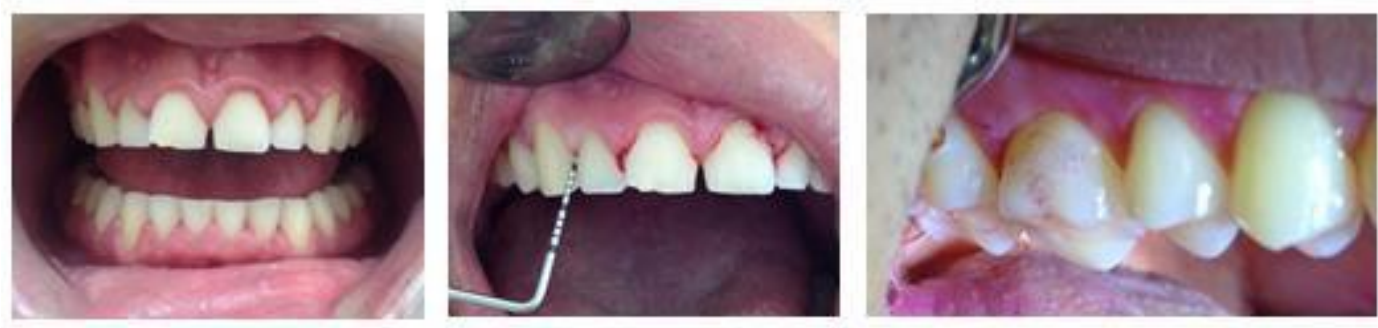

Figura $N^{\circ}$ 1.- Características de la encía con enfermedad; 2. Sangrado al sondaje; 3. Cemento ortodóntico remanente

\section{Resultados.}

\section{Terapia Básica Periodontal.}

Después de los raspados y alisados radiculares, se realiza una encuesta sobre los síntomas subjetivos del dolor a los 30 min, 24 horas, y a los 8 días se evalúa clínicamente y mediante la encuesta. A los 30 min después de realizado el procedimiento el paciente refirió que sintió ardor en el momento de colocación del propóleo pero que el ardor cesó minutos después. En relación a los síntomas subjetivos del dolor, de acuerdo a la escala numérica de dolor el paciente se ubicó en el número 1.

\section{Vol. 3, núm. 1, enero, 2017, pp.}


Al siguiente día se le volvió a realizar una encuesta. El paciente refirió que no tomó el medicamento recetado para el dolor y la inflamación, pero a pesar de esto el paciente no tuvo dolor en ningún momento, es decir, de acuerdo a la escala numérica de dolor el paciente se ubicó en el número 0.

En el control realizado a los 8 días, se observó que el tejido periodontal ya no presentaba inflamación. Pudimos observar que recuperó la salud periodontal ya que se perdió el sangrado al sondaje, las encías ya no tenían la coloración roja intensa, sino que ahora tenía un color rosa pálido, la textura ya no era lisa dado que el punteado en cáscara de naranja había sido recuperado, y las encías ya no se veían tan agrandadas como cuando el paciente acudió a la consulta. El paciente refirió que no sintió dolor ni molestia alguna con ninguna actividad o alimento. (Figura $\boldsymbol{N}^{\circ} 2$ )

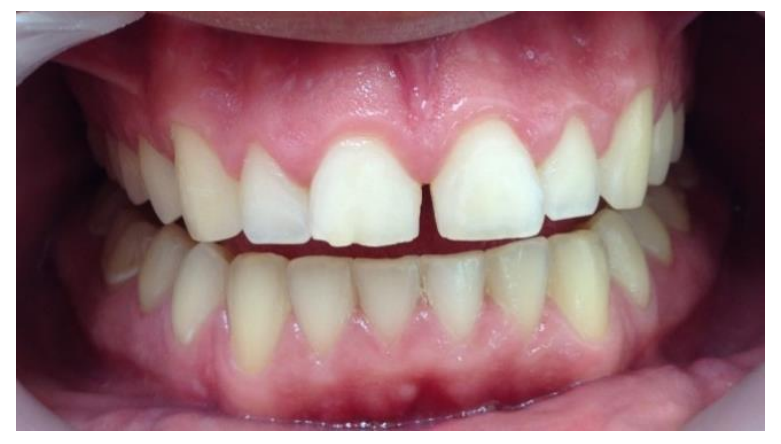

\section{Figura $N^{\circ}$ 2.- Evaluación a los 8 Días después de la Terapia Básica Periodontal}

\section{Cirugía Plástica Periodontal:}

Para la evaluación de la cirugía plástica periodontal, se realizaron evaluaciones a las 24 horas, 48 horas y 8 días tanto de los aspectos clínicos del tejido gingival como de los síntomas subjetivos del dolor y comodidad mediante una encuesta, comparando el área quirúrgica superior con la inferior. 
El día de la cirugía plástica periodontal se realizó la primera encuesta 30 minutos después de acabada la cirugía. El paciente refirió que la zona quirúrgica superior le ardía debido a la colocación del propóleo, pero este ardor fue ausente en la zona inferior que tenía el apósito quirúrgico de óxido de zinc-eugenol, solo refirió haber sentido una picazón que fue producida por el eugenol.

En cuanto a los síntomas subjetivos del dolor, en la escala numérica de dolor el paciente refierió tener un dolor nivel 3 cuando se mantiene inmóvil, pero cuando realiza movimientos bucales el dolor sube a un nivel 5, tanto en el área quirúrgica superior como en la inferior. En cuanto a la comodidad, el paciente refirió tener gran incomodidad en la mandíbula en comparación con el maxilar debido al apósito quirúrgico que, por su grosor, ubicación y coloración comprometía la estética y le estorbaba.

En la valoración clínica posquirúrgica, observamos que al terminar la cirugía y colocar el propóleo se consiguió una hemostasia inmediata del área quirúrgica mientras que en el área mandibular, la hemostasia tardó más tiempo e incluso mancho al apósito quirúrgico. El tejido tenía un color rojo intenso con textura lisa y brillosa, se observa tumefacta la zona tratada pero el festoneado se encuentra normal. (Figura $\left.N^{\circ} 3\right)$
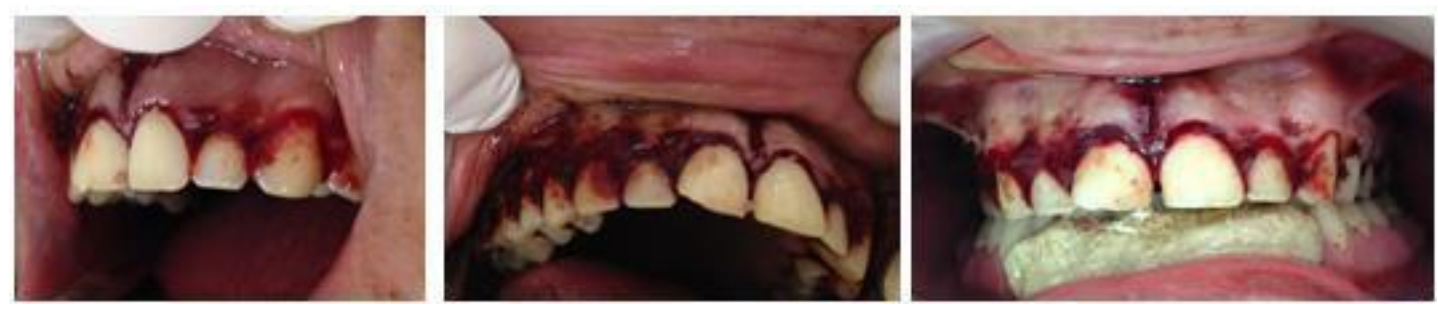

Figura $N^{\circ}$ 3.- Hemostasia después de la Colocación del Propóleo; Cirugía Periodontal Finalizada 
La segunda evaluación clínica y de los síntomas subjetivos del dolor lo realizamos al día siguiente de realizada la cirugía. Al examen clínico observamos que el tejido de cicatrización ha empezado a formarse, y que la papila entre los dientes 1.1 y 1.2 estaba inflamada lo cual, según el paciente, produjo un ligero sangrado de esa papila al momento del cepillado de dientes. El paciente cuenta que solo se ha realizado cepillado de dientes con posterior uso de enjuague bucal a base de clorhexidina al $0,12 \%$, pero no ha realizado limpieza directa de sus encías. La zona del frenillo no pudo ser vista ya que el paciente presentaba dolor al movimiento. En la evaluación del maxilar observamos que el apósito quirúrgico se mantuvo en una correcta posición cubriendo toda el área quirúrgica mandibular. (Figura $\left.N^{\circ} 4\right)$

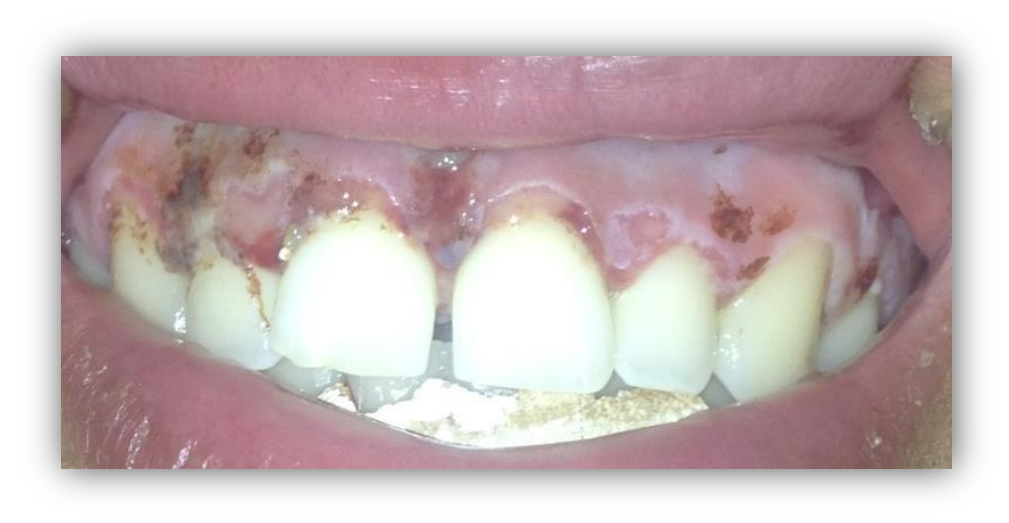

Figura $N^{\circ}$ 4.- Evaluación a las 24 horas Posquirúrgico

En cuanto a los síntomas subjetivos del dolor, en la escala numérica de dolor para el maxilar el paciente se colocó en el número 1 cuando no realizaba movimientos significativos como hablar, es decir un dolor continuo, pero se colocó en el número 4 al momento de realizar movimientos significativos como mojar sus labios con la lengua, reír de forma exagerada o al tacto. Este dolor grado 4 que el paciente refirió estaba más limitado a la zona del frenillo que a la zona de encías, y el paciente contó que sentía el dolor por los puntos realizados en la frenectomía, y que la sutura le

\section{Vol. 3, núm. 1, enero, 2017, pp.}

Verónica E. Salazar-Caicedo; Mariela C. Balseca-Ibarra; Alicia C. Martínez-Martínez 
resultaba molestosa. En relación a la mandíbula, el paciente refirió haber tenido un dolor constante grado 3 según la escala numérica de dolor. El paciente contó que el apósito quirúrgico inferior le estorbaba mucho y que no había tomado ningún medicamento en el transcurso del día, solo tomó una tableta de ibuprofeno 3 horas después de realizada la cirugía.

Dos días después de la cirugía realizamos el tercer control clínico junto con la valoración de los síntomas subjetivos del dolor. En este día también se retiró el apósito quirúrgico presente en la mandíbula. En el maxilar observamos que el paciente se realizó una mejor limpieza local de la zona quirúrgica después de haber cepillado sus dientes y usado el enjuague bucal a base de clorhexidina. Observamos que la cicatrización avanzó significativamente, el tejido gingival se observó de color rojo brilloso, y exhibía tejido en proceso de cicatrización en la papila entre los dientes 1.1 y 1.2, y en la zona del frenillo que baja por la línea media hasta la papila interdental de los dientes 1.1 y $2.1 \mathrm{La}$ papila entre los dientes 1.1 y 1.2 presenta sangrado espontáneo y al cepillado, lo que demuestra que mantiene una inflamación que puede deberse a restos de biofilm duro. A excepción de esta papila interdental, todo el tejido gingival ha tenido una cicatrización satisfactoria.

En la mandíbula, observamos que el tejido presenta un color rojo intenso y brillante, se observa proceso de cicatrización en los márgenes gingivales y papilas interdentales de los dientes inferiores. La papila entre los dientes 4.1 y 4.2 presenta un ligero sangrado espontáneo. (Ilustración 5) 

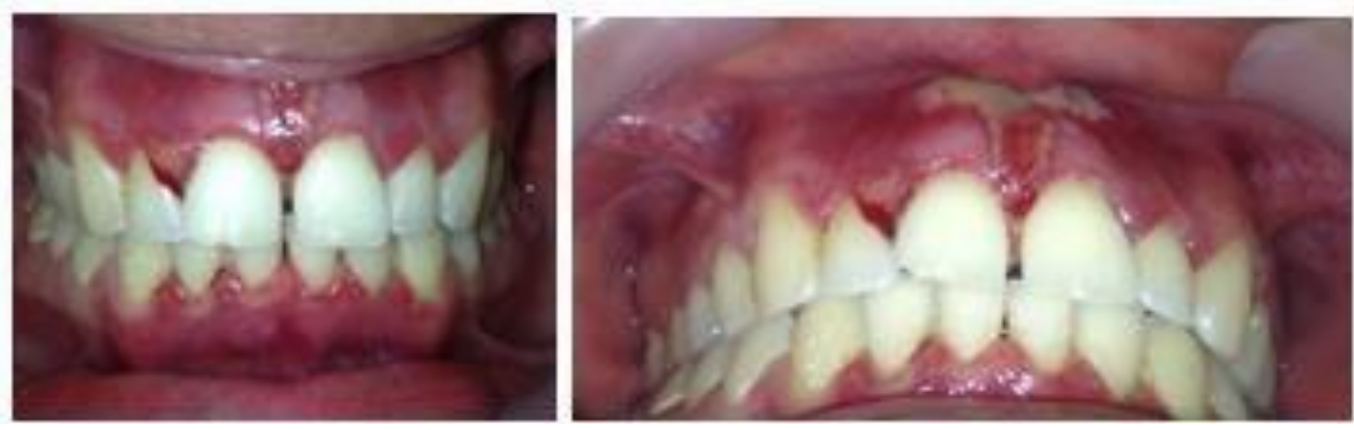

\section{Figura $N^{\circ}$ 5.- Evaluación a las 48 horas Posquirúrgico}

En cuanto a los síntomas subjetivos del dolor del maxilar, el paciente refiere sentir dolor solo en la zona del frenillo debido a los puntos de la frenectomía, por lo cual no puede realizar movimientos significativos con el labio superior. Sin embargo, este dolor redujo en comparación con el día anterior siendo este dolor un dolor grado 2 según la escala numérica del dolor. A nivel de la gingiva el paciente refirió no sentir dolor alguno, es decir, dolor grado 0 según la escala numérica, solo tenía un leve dolor en la papila interdental de los dientes 1.1 y 1.2 al momento del cepillado.

En la mandíbula el dolor que presentaba el paciente redujo a un dolor grado 2 según la escala numérica del dolor, pero este se intensificó un poco con el retiro del apósito quirúrgico. El paciente calificó a este dolor como grado 4 según la escala numérica y visual de gestos faciales, pero este a los 20 minutos redujo a un dolor grado 2 según la escala numérica y visual de gestos faciales. El paciente no ha tomado ninguna medicación para el dolor e inflamación.

En la evaluación clínica ocho días después de la cirugía, observamos que a excepción de la papila interproximal de los dientes $1.1 \mathrm{y}$ 1.2, la gingiva tanto superior como inferior ha cicatrizado satisfactoriamente. A nivel del frenillo labial, en la zona de la sutura se observa la acumulación de tejido necrótico como resultado de la fase final de la cicatrización. (Figura $\boldsymbol{N}^{\circ} \boldsymbol{6}$ )

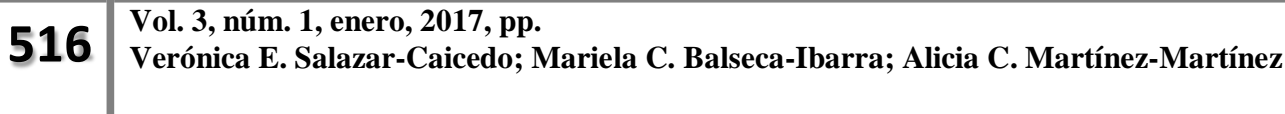



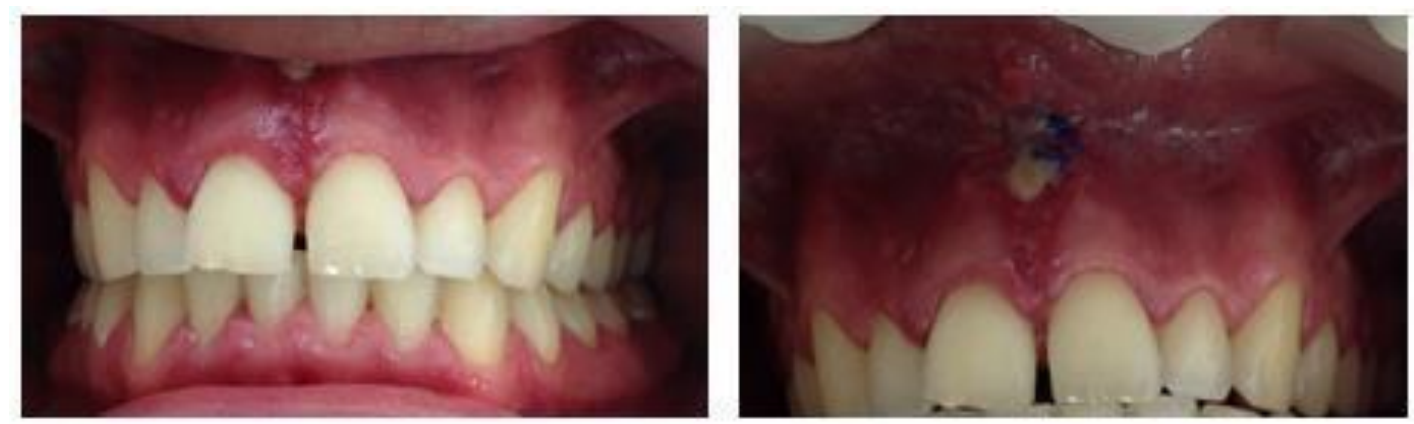

\section{Figura $N^{\circ}$ 6.- Control a los 8 Días Posquirúrgico}

En esta cita se realizó la remoción de puntos de la frenectomía. Al haber retirado los puntos observamos que en la zona del frenillo aún no se ha cicatrizado totalmente el tejido así que procedemos a colocar tintura de propóleo al 0,12\% en forma de goteo. $\left(\right.$ Figura $\boldsymbol{N}^{\circ} 7$ )
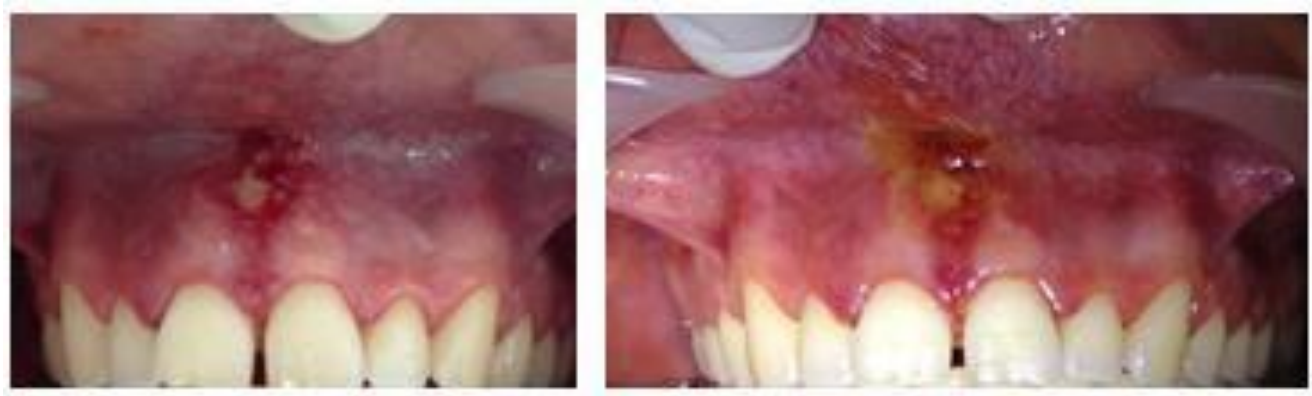

Figura $N^{\circ}$ 7.- Frenillo no cicatrizado Posterior al Retiro de Puntos; Colocación de Propóleo en el

\section{Frenillo Labial}

En cuanto a los síntomas subgetivos del dolor, el paciente refiere tener un dolor grado 0 en la escala numérica del dolor tanto para las encías de la arcada superior como la inferior, pero refirió sentir un dolor grado 2 en la zona del frenillo según la escala numérica y visual del dolor.

En el transcurso de la recuperación quirúrgica el paciente refirió no haber fumado ni una sola vez y que mantuvo una correcta higiene bucal.

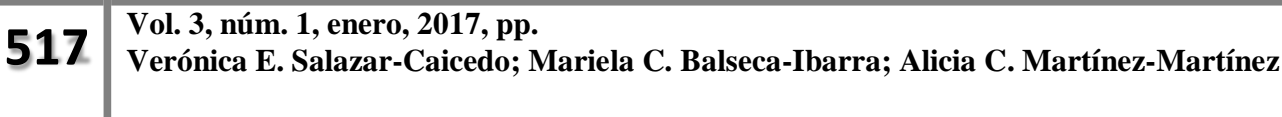


En el siguiente control periodontal, en la reevaluación después de haber finalizado la fase correctiva, observamos que se recuperó el nivel de inserción en los dientes que presentaban bolsas periodontales verdaderas. En cuanto a los dientes que poseían pseudobolsas, estas fueron eliminadas después de la cirugía plástica periodontal, por lo que todos los dientes presentaron márgenes gingivales a nivel de LAC y profundidades de sondaje no mayores a $3 \mathrm{~mm}$.

\section{Discusión.}

El propósito del presente estudio fue comparar la efectividad del propóleo y el apósito quirúrgico a base de óxido de zinc-eugenol en la cicatrización de un paciente sometido a tratamientos periodontales higiénicos y correctivos. Al tener una rápida cicatrización, se garantiza al paciente un mayor confort posquirúrgico.

El propóleo ha sido administrado de forma tópica y sistémica en diferentes vehículos con el propósito de modular la cicatrización de heridas quirúrgicas. Administrado tópicamente, el propóleo tiene la capacidad de penetrar en la herida. Esta capacidad de penetración fue demostrada en un estudio hecho por Sehn y cols, usando espectroscopia fotoacústica. (9) Los apósitos quirúrgicos por su parte, no tienen la capacidad de penetrar la herida ya que según Lindhe J, 2011, (10) los apósitos periodontales se usan principalmente para proteger la herida en el posoperatorio.

El propóleo aplicado en cirugías orales post extracciones dentarias tuvo efectos positivos sobre la epitelización y aceleración de la cicatrización de las heridas. Premoli, G; et al, 2010, (8) afirma que el propóleo actúa directamente en la cicatrización al estimular la actividad fibroblástica. De la misma manera, Asís M, 2007, (11) y Lopes R; et al, 2012, (9) manifiestan que actúa como excelente hemostático. Según Newman M; et al, 2010, (12) los apósitos no tienen propiedades

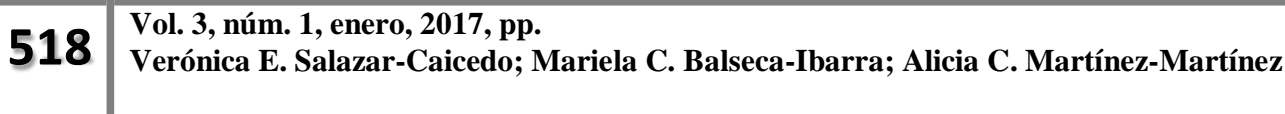


curativas; en la cicatrización ayudan a proteger el tejido más que a proporcionar "factores de cicatrización”. El apósito reduce la probabilidad de infección y hemorragia posoperatorias, y facilita la cicatrización al evitar el traumatismo de la superficie durante la masticación.

Asís M, (11) expone que el propóleo actúa reduciendo el dolor y la inflamación por medio de la inhibición de la lipooxigenasa y ciclooxigenasa que son las responsables de las respuestas inflamatorias. Newman M; 2010, (12) por su parte dice que los apósitos periodontales no calman el dolor, sino que protegen contra el dolor originado por el contacto de la herida con los alimentos o la lengua durante la masticación.

\section{Conclusiones.}

Después de haber finalizado con el tratamiento podemos concluir que gracias a la satisfactoria realización de todos los procedimientos previamente planificados, se ha devuelto la estética y salud integral al paciente. Se logró cumplir con el principal objetivo de hacer la topicación de la tintura de propóleo el 0,12\% para acelerar la cicatrización. El propóleo ayudó significativamente en la recuperación postoperatoria de la terapia básica periodontal gracias a la eliminación del dolor y la inflamación; en la recuperación de la cirugía plástica periodontal redujo significativamente el dolor en las primeras 24 horas, y lo eliminó por completo al cabo de las 48 horas.

En comparación con el apósito periodontal, el propóleo resultó ser más cómodo y hemostático que el apósito. El apósito periodontal es más incómodo debido a su grosor, su retención de placa y su pobre estética. No se pudo realizar una comparación certera en cuanto al tiempo de

\footnotetext{
519 Vol. 3, núm. 1, enero, 2017, pp. 
cicatrización; a simple vista se puede creer que el propóleo fue más efectivo, pero para comprobarlo se necesitarían muestras histológicas cada cierto tiempo.

\section{Bibliografía.}

1. Pérez L, De Armas A, Fuentes E. Prevalencia de enfermedad periodontal y factores de riesgo asociados. Ciencias Médicas. 2011; 15(2): p. 53-64.

2. Echeverría J. Enfermedades Periodontales y Periimplantarias. Factores de riesgo y su diagnóstico. Avances en Periodoncia e Implantología oral. 2011; 15(3): p. 149-156.

3. Martínez J. Raspado y Alisado Radicular, una técnica que llego para quedarse. Revista Médica Odontológica. 2007; 29(1).

4. Caviglia S, Aún M, González M, Cabrera C, Rosso V, Vázquez D, et al. Hiperplásia Gingival Idiopática. Diagnóstico y tratamiento de un saso clínico y revision de la literatura. Revista ADM. 2011; 68(5): p. $254-257$.

5. Alvarado-Torres E, Rojas-García A. Efectos Indeseados en el tratamiento Ortodoncico. Revisión de la literatura. Revista Latinoamericana de Ortodoncia y Odontopediatria. 2015.

6. Burgos T, Palomino D, Diaz A. Gingivectomía a bisel externo. Revista de la Facultad de Ciencias de la Salud. 2008; 5(2): p. 125-128.

7. Saiz M. Apiterapia, las propiedades del propóleo. Mi Herbolario. Revista Especializada oara Profesionales de la Salud. 2012.

8. Premoli G, Laguado P, Díaz N, Romero C, Villarreal J, González A. Uso del Propóleo en odontología. Acta Odontológica Venezolana. 2010; 48.

9. Lopes R, Miranda J, Lima N, Ferreira F, Santos A, Marinho S, et al. Effect of topical propolis and dexamethasone on the healing of oral surgical wounds. Wound Healing Sothern Africa. 2012; 5(1): p. pp. 25-30.

10. Lindhe J. Periodontología clínica e implantología odontológica. 5th ed. Buenos Aires: Panaericana; 2011.

11. Asís M. APITERAPIA 101 PARA TODOS: Cómo usar los siete productos de la colmena para curar a una comunidad. 3rd ed. Florida,: Autor; 2007.

12. Newman M, Klokkeuold F, Takei P. Carranza periodontologia clínica. 10th ed. México: McGraw-Hill; 2010.

\footnotetext{
520 Vol. 3, núm. 1, enero, 2017, pp.

Verónica E. Salazar-Caicedo; Mariela C. Balseca-Ibarra; Alicia C. Martínez-Martínez
} 